\title{
Kinematics of ductile shear zones with deformable or mobile walls
}

\author{
Kieran F Mulchrone ${ }^{1, *}$ and Soumyajtt MukherjeE ${ }^{2}$ \\ ${ }^{1}$ Department of Applied Mathematics, School of Mathematical Sciences, University College, Cork, Ireland. \\ ${ }^{2}$ Department of Earth Sciences, Indian Institute of Technology Bombay, Powai, Mumbai, Maharashtra 400076 , \\ India. \\ *Corresponding author.e-mail: k.mulchrone@ucc.ie
}

MS received 22 May 2018; revised 21 February 2019; accepted 16 May 2019

Shear zones are important phenomena in the Earth's middle and lower crust and are of great interest to structural geologists. Models involving rigid boundaries moving parallel to themselves are extended here to include the case where (i) walls are deformable and (ii) mobile rigid walls approach each other. These models are combined with Couette and Poiseuille flow to define a broad range of kinematic possibilities. Deformable wall models lead to smooth transitions from deformed to undeformed materials as well as with the zone transitions to gentler and more spread out deformation. Mobile walls, on the other hand, lead to shear zones where shear sense can change along a shear zone boundary.

Keywords. Shear zone kinematics; rheology; structural geology; deformation mechanism; Couette flow; fluid mechanics.

\section{Introduction}

Ductile shear zones at different scales of observation are intensely studied by structural geologists because, in addition to theoretical reasons (Fossen and Cavalcante 2017), these zones define major plate boundaries and are the loci of seismicity (Regenauer-Lieb and Yuen 2003). Taking the simplest case of a shear zone with parallel rigid boundaries, several kinds of ductile shear have been recognised: (i) simple shear/Couette flow: where one or both the boundaries move parallel to themselves (figure 1a; Ramsay 1980); (ii) pure shear/cream-cake model: the boundaries move perpendicular to themselves (figure 1b; Mukherjee submitted), (iii) general shear/sub-simple shear: the boundaries move in a way that have both simple- and pure shear components (figure 1c; Vannay and Grasemann (2001) in a tectonic context); (iv) Poiseuille flow: the boundaries of the shear zone remain static and an along zone pressure difference causes flow along the shear zone (figure 1d; Beaumont et al. 2001); and (v) combined simple shear and Poiseuille flow: the boundaries shear past each other along with a pressure gradient-induced fluid flow inside the zone (figure 1e; Mukherjee and Koyi 2010). Recently, these different ductile shear mechanisms have been discussed and debated vigorously in the context of extrusion of portions of large, hot orogens, such as the Greater Himalayan Crystallines (Appendix of Mukherjee 2013a). At a much smaller scale, flow of partially molten material through brittle planes can follow a Poiseuille flow mechanism during the ductile shear process. Assuming an incompressible Newtonian rheology for material inside the shear zone, velocity profiles for simple shear through a horizontal shear zone are linear, and for all other 


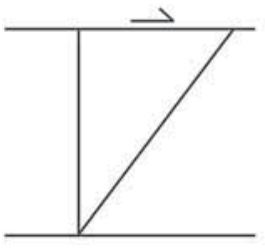

a

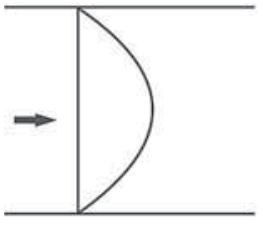

d

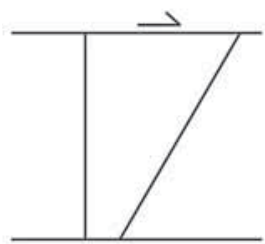

g

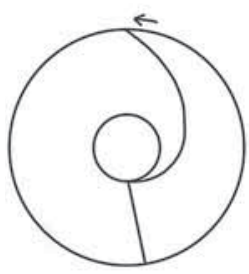

j

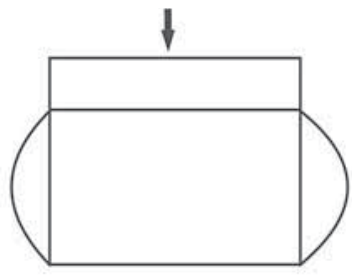

b
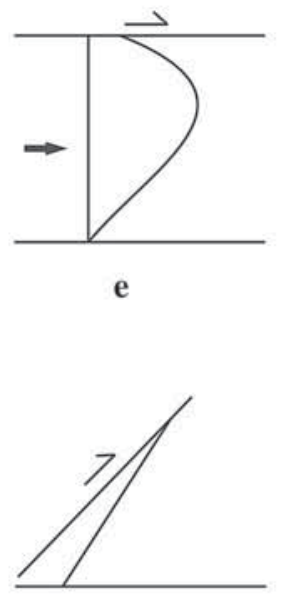

h

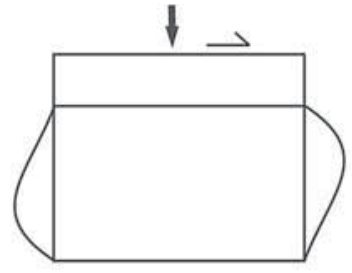

c

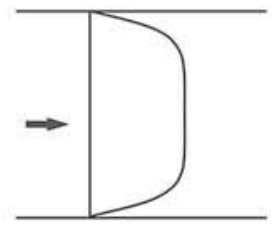

f

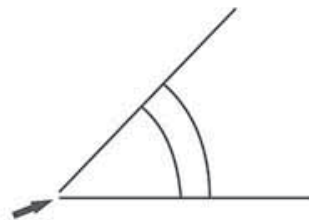

i

Figure 1. Ductile shear kinematics. Parallel boundary cases: (a) Simple shear; (b) Pure shear; (c) General shear, (d) Poiseuille flow of a Newtonian fluid; (e) Combined simple shear and Poiseuille flow; (f) Poiseuille flow of a non-Newtonian fluid. Nonparallel boundary cases: (g) Slipping boundary; (h) Simple shear with tapering boundaries; (i) Jeffery Hamel flow of Newtonian fluid. (j) Simple shear within a circular zone. Refer to section 1: Introduction.

ductile shear types referred above they look parabolic. For non-Newtonian rheology, Couette flow profile is non-specific (Hobbs 1972), and for a purely Poiseuille flow bell-shaped (figure 1f; Turcotte and Schubert 2014).

Besides, these common ductile shear patterns, Mandal et al. (2002) analogue modelled flow kinematics for tapering ductile shear zones with rigid walls (figure 1h). Mukherjee et al. (2012) mechanically modelled ductile extrusion through a shear zone that converges at depth (figure 1i). Mukherjee and Biswas (2014, 2015) analytically modelled simple shear flow profile through circular horizontal shear zones (figure 1j). Mulchrone and Mukherjee (2016) investigated the simple shear with or without Poiseuille flow for slipping boundary cases (figure $1 \mathrm{~g}$ ).
The possibility of shear zones with deformable or mobile boundaries has been recognised for some time (Bailey et al. 2004 and references therein) but their kinematic details are not well known. For example, Lisle (2014) analysed the kinematics of ductile deformation assuming the rigid boundaries. Flattening/pure shear of a zone with deformable walls was analysed only by Mandal et al. (2001). Their kinematic analysis involves a parameter that defines the competency contrast between the shear zone rock and its wall rock. Ductile sheared migmatites can be characterised by leucosome layers defining the primary shear planes near which alternate layers of leucosomes and melanosomes swerve defining S-fabrics (Mukherjee 2010). The occurrence of leucosome layers along C-planes indicates the syntectonic/syn-shear migmatisation 
(Marchildon and Brown 2003). While undergoing migmatisation, the leucosome was in a fluid stage. We, therefore, interpret the common observations that such $C$-planes are not perfectly planar (figure $2 \mathrm{a}, \mathrm{b}$ ), as an indication of internal ductile deformation of the soft fluid layer. Lloyd et al. (1992) reported the deformed shear zone margins at the grain scale from mylonites in Scotland. Zhang et al. (2012) document the deformed footwall of a shear zone from Yiwulushan (China), both having similar kinematic indicators. Roy Choudhury et al. (2016) documented the deformation in the footwall of a mylonitised shear zone (Rajasthan, India).

It will be important not to compare the present model with cases where the shear zone boundary deformed after the ductile deformation e.g., a brittle deformed margin in a metamorphic core complex (Davis 1983).

Shear zone boundaries act rigidly when the ratio of viscosity between the shear zone and the surrounding rocks is $\leq 10^{-7}$ (Mancktelow 2008). However, inside such rigid "...boundaries, the softer rock would produce primary shear planes parallel to the boundaries of the shear zones" (Passchier and Trouw 2005). Note that we do not mean those $C$ planes to act as shear zone boundaries in this paper. Such $C$-planes to are locally found to be warped

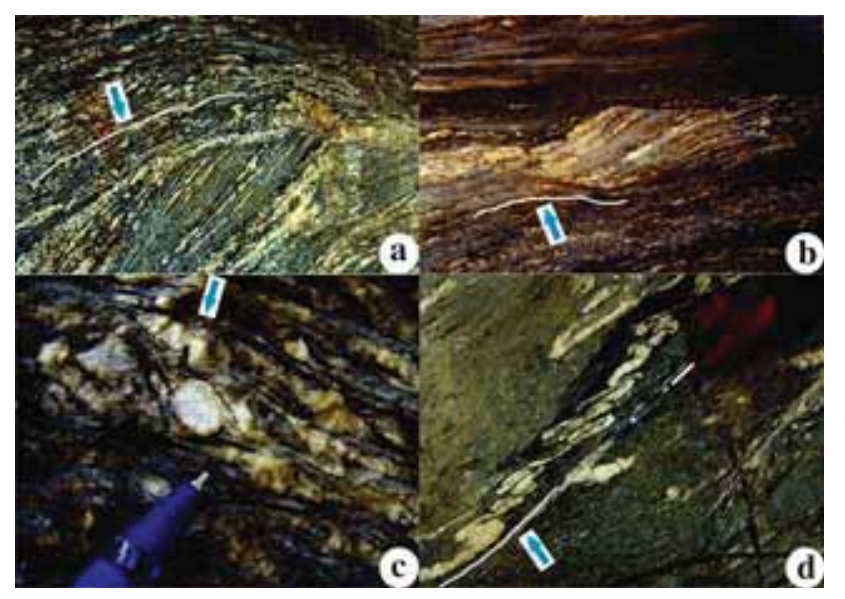

Figure 2. Ductile shear zones in meso-scale, with non-planar $C$-plane. Reproduced from figures 1.4, 1.5, 1.49 and 2.7, respectively, of Mukherjee and Biswas (2014). Blue full arrow: curved C-plane. (a, b) S-fabric defined by thicker leucosome and thinner and close-spaced melanosome layers $C$-plane traces white line. Top-to-S (top-to-right) shear. Greater Himalayan Crystallines, Sutlej river section, Himachal Pradesh state, India. (c) A delta structure of quartz clast. Top-toS (top-to-left up) sheared. Bhagirathi section of Greater Himalayan Crystallines, India. (d) A train of intrafolial fold (Mukherjee and Biswas 2015) bound by $C$-planes. Top-to-NE down (top-to-left down) sheared. Near Karcham, Himachal Pradesh, Sutlej river section, Greater Himalayan Crystallines, India.
(Mukherjee 2013b). In phyllites, the ratio of viscosity between mica-poor and mica-rich layers ranges 1-2 (Bayly 1970). Except for a single estimate of viscosity $\left(10^{21}-10^{22} \mathrm{~Pa} \mathrm{~s}\right)$ for a feldspar-rich rock at high temperatures (Rybacki et al. 2002), viscosity magnitudes of ductile deforming micas, quartz and feldspar are largely unknown. In the ductile regime, below $8-15 \mathrm{~km}$ depth, there is no guarantee that the shear zone material deforms in a ductile manner while simultaneously the surrounding rocks behave rigidly.

Mica-rich layers defining narrow shear zones inside a quartzofeldspathic matrix are common in many rock types (e.g., Mukherjee 2013b), where the shear zone boundaries are defined by preferred alignment of micas that are recognised also as C- or primary shear planes (Passchier and Trouw 2005). We presently neither have viscosity magnitudes nor ratios of such micas and quartzofeldspathic minerals to compare whether theoretically such mica layers can act rigidly during the shear. A common observation, however, is that such mica layers are not always perfectly straight in meso(figure $2 \mathrm{a}-\mathrm{d}$ ) and micro-scales (figure $3 \mathrm{a}-\mathrm{d}$ ), possibly indicating that mica layers acted as deformable boundaries of such shear zones. A similar conclusion can be drawn from ductile shear zones recognised on mega-scales using the remote sensing images (Pour and Hashim 2016). C-planes are readily recognised based on sharp termination/ swerving of S-fabrics and are clearly curving in exposures and therefore must also be curvi-planar in $3 \mathrm{D}$.

Note that at smaller scales step-overs (of mica fish trails denoting the mylonitic foliation/ $C$-plane: Lister and Snoke 1984) and possibly intrafolial folded $C$-planes indicate ductile shear of the $C$ plane themselves. Thus, there is a need to extend the kinematic theory of ductile shear zones to include the case of deformable and mobile boundaries in structural geology.

All analogue and most numerical models of shear zones in structural geology and tectonics tend to consider the rigid boundaries. Curviplanar margins of shear zones were implicitly presumed to be predeformational. Curved primary ductile shear planes in meso-scales (Coward 1976) and in hand specimens (Gapais et al. 1987) are well known. Hyperbolic- and linear flow paths for pure and simple shear zones (Schlichting 1960) have also been well established. However, the velocity proles for shear zones with deformable boundaries have not been explored. 


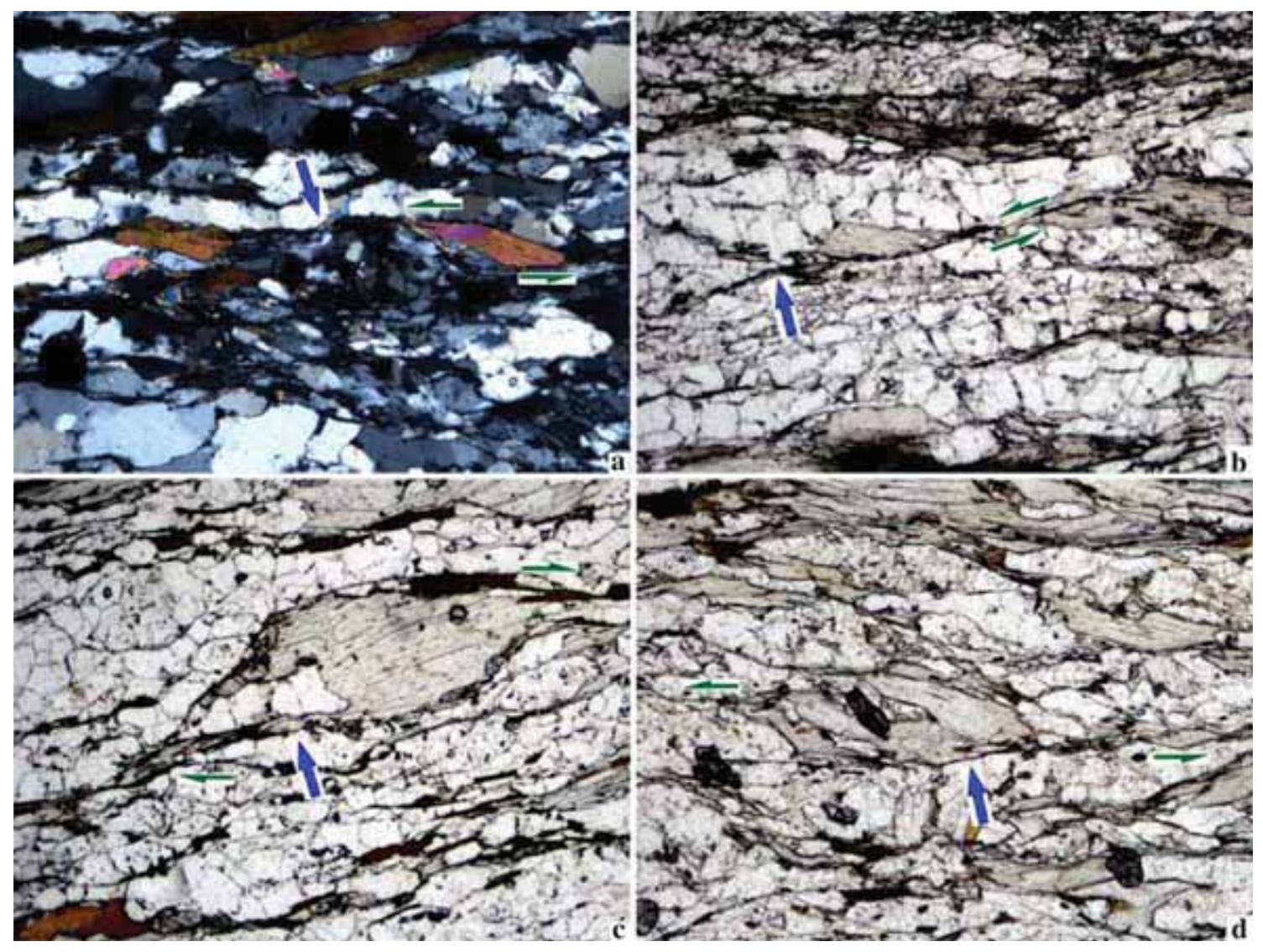

Figure 3. Ductile shear zone within mylonitized gneiss in micro-scale, with non-planar $C$-plane, all photomicrographs lengths are $0.24 \mathrm{~mm}$. Tso Morari Crystallines, Ladakh, Jammu \& Kashmir state, India. Blue full arrows points out non-planar C-plane, (a) Top-to-left sheared "muscovite fish" (Mukherjee 2011). The quartz layer above the fish is warped. Top-to-SW (top-to-left) sheared. Cross-polar. Sample location: latitude: 33.23078 .320 , longitude: 78.320; $2 \mathrm{~km}$ E of Puga. (b) The muscovite fish is rather irregular-shaped. Top-to-W down (top-to-left down) sheared. Plane polarized light. Location: latitude-33.240, longitude78.210. (c) Top-to-W (top-to-right) sheared muscovite fish. Plane polarized light. Location: latitude-33.240, longitude-78.210. (d) Top-to-SW (top-to-left) sheared muscovite fish. Plane polarized light. Location: latitude-33.240, longitude-78.210.

This work investigates the kinematics of ductile shear zones using relatively simple mathematical models that consider the case of (i) deformable walls and Couette flow, (ii) deformable walls and Poiseuille flow, (iii) mobile walls and Couette flow and finally (iv) mobile walls and Poiseuille flow.

Linear stability analyses for Newtonian (Gkains and Kumar 2006) and non-Newtonian fluid flow (Roberts and Kumar 2006) through deformable tube/media have already been performed in fluid mechanics, but its geological implications and the relevant velocity profile studies have not been explored so far.

\section{Mathematical models}

\subsection{Introduction}

Two classes of mathematical models are introduced for shear zones at any scale with deforming walls and those with rigid but mobile walls. In each case, the shear zone may also experience either Couette or Poiseuille flow or both. The ductile material is modelled by an incompressible Newtonian rheology. Equations are derived for the velocity fields inside and outside the shear zone, wherever appropriate. The chosen 1D pipe flow equation does not explain all of the deformation features in natural shear zones such as secondary shears. The models consider active velocity " $u$ " as a function of the "y-direction", which is perpendicular to the length of the shear zone. This is because compression acts along that direction. The models also consider the movement of shear zone material along the length of the shear zone.

\subsection{Deformable walls}

A sketch of the situation considered is shown in figure 4 where the walls deform synkinematically. 
a

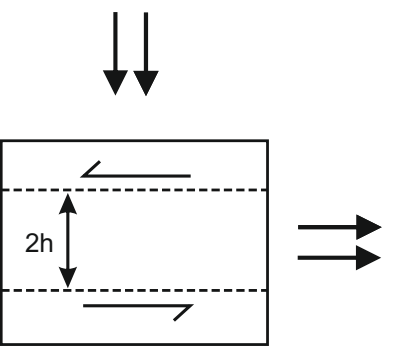

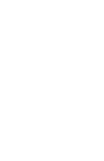

b

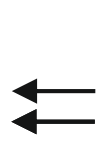

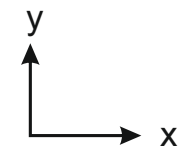

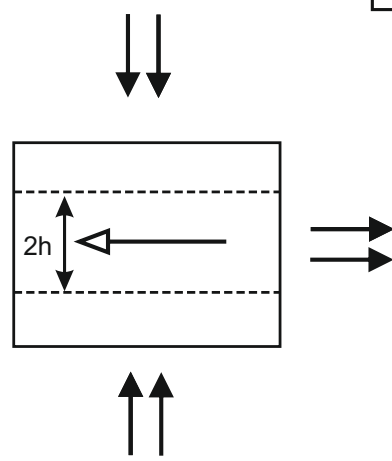

Figure 4. (a) Depiction of mathematical model for deformable walls and Couette (shear) flow. The shear zone is the region between the dashed lines and the sense of shear is indicated by the half arrows. The zone is of total width $2 h$. Pure shear affects the whole region and is indicated by the black arrows. The pure shear is shown such that the extension direction parallels the long direction of the shear zone. In the more general situation considered in the text, the pure shear may be rotated through an angle $\phi$. (b) This is identical to the the situation in (a) except that there is no shearing motion of the walls and a pressure gradient depicted by the open arrow is present. The width between the dashed lines in each case is $2 h$ and this does not change as a function of time.

The shear zone is the region between the dashed lines and in the case of Couette flow the upper and lower walls move parallel to each other as shown (figure 4(a)). Several ductile shear zones have been interpreted to have a dominant simple shear component (e.g., Lloyd 2004). For this reason, the simple shear zones have been modelled under various constraints over the last few decades (e.g., Ramsay 1980). However, the simple sheared ductile material must also compress in order to avoid a space conservation problem, which has not been considered by the previous modellers or in this study. The entire region is simultaneously subject to a pure shear, as indicated by the black arrows, which deforms both the materials outside the walls and inside the shear zone. The width of the shear zone does not change over time, which means that the material is progressively moved into the shear zone. In the case of

Poiseuille flow (figure 4(b)) a pressure gradient is present inside the shear zone (between the dashed lines), again the shear zone width is constant and the entire region is subject to pure shear. If the pure shear did not affect the entire region, e.g., stopped at the shear zone boundary, then a discontinuity would be present and the model would be invalid. It is not proposed that this description conforms exactly to actual physical situations; however, it is a reasonable first-order approximation in some cases. The models are inherently non-linear and cannot be readily solved analytically. Here they are solved numerically using Mathematica to generate velocity fields and movement patterns.

Along the shear zone pressure gradients are a requirement for the Poiseuille flow to occur (Mukherjee and Mulchrone 2013). This gradient may be due in part to density differences between the material inside and outside the shear zone, in particular if the shear zone is inclined with respect to the horizontal. For example, if the shear zone is inclined at an angle $\alpha$ and density of the material inside the shear zone is $\rho_{c}$ and outside the zone it is $\rho_{b}$ then the gradient $G=\left(\rho_{b}-\rho_{c}\right) \sin \alpha$.

Consider a shear zone parallel to the $x$-axis of width $2 h$ and let the velocity in the $x$-direction be $u$ and that in the $y$-direction be $v$. Suppose there is a pressure gradient acting along the channel such that $d p / d x=-G$. Additionally, there are boundary conditions (on the shear zone boundary): $u(x, h)=U_{s}$ and $u(x,-h)=-U_{s}$. Then the governing equation for the flow the inside the shear zone is (Turcotte and Schubert 2002, pp. 227-228):

$$
\mu \frac{d^{2} u}{d y^{2}}=\frac{d p}{d x}=-G
$$

with the solution:

$$
u(x, y)=\frac{U_{s}}{h} y+\frac{G\left(h^{2}-y^{2}\right)}{2 \mu} .
$$

However, taking into account the pure shear ocurring on both inside and outside the shear zone the full expression for the velocity field is:

$$
u(x, y)=\left\{\begin{array}{cc}
\dot{\epsilon} x+\frac{U_{s}}{h} y+\frac{G\left(h^{2}-y^{2}\right)}{2 \mu}, & -h \leq y \leq h \\
\dot{\epsilon} x+U_{s}, & y>h \\
\dot{\epsilon} x-U_{s}, & y<-h \\
v(x, y)=-\dot{\epsilon} y, &
\end{array}\right.
$$


where $\dot{\epsilon}$ is the strain rate of the pure shear component. Positive $\dot{\epsilon}$ means stretching along the axis of the shear zone and negative $\dot{\epsilon}$ implies compression along the axis of the shear zone. These equations can be solved to determine the position of any point as a function of time.

The most general case is the one in which the principal extension direction pure shear component does not necessarily parallel the long direction of the shear zone. This can be accommodated by applying a rotation of $\phi$ to the pure shear. Furthermore, the above expression can be written more succinctly in terms of the Heaviside or unit step function defined as follows:

$$
U(y-\alpha)= \begin{cases}1, & y \geq \alpha \\ 0, & y<\alpha\end{cases}
$$

Therefore, the general expressions governing the position of material particles inside and outside the shear zone are:

$$
\begin{aligned}
& u(x, y)=\frac{d x}{d t} \\
& =\left[\begin{array}{c}
\left(\alpha+\frac{U_{s}}{h} y+\frac{G\left(h^{2}-y^{2}\right)}{2 \mu}\right)(U(y+h)-U(y-h)) \\
\left.+\left(\alpha+U_{s}\right) U(y-h)+\left(\alpha-U_{s}\right)(1-U(y+h))\right)
\end{array}\right]
\end{aligned}
$$

$$
\begin{aligned}
v(x, y)= & \frac{d y}{d t}=2 \dot{\epsilon}(\cos \phi \sin \phi) x \\
& +\dot{\epsilon}\left(\sin ^{2} \phi-\cos ^{2} \phi\right) y
\end{aligned}
$$

where

$$
\alpha=\dot{\epsilon}\left(\cos ^{2} \phi-\sin ^{2} \phi\right) x+2 \dot{\epsilon}(\cos \phi \sin \phi) x .
$$

The pair of the differential equations above can be solved for the position of points in the system studied as a function of time. This is a non-linear system of equations due to the presence of quadratic terms and also because the Heaviside function is highly non-linear.

\subsection{Mobile walls}

An alternative model concerns the case where the walls are rigid but mobile, i.e., they move towards or apart from each other. The model is a specific ideal case where the thickness of the shear zone varies with progressive deformation and the shear zone possesses rigid mobile walls. This is the "cream-cake" model described by Jaeger (1969, pp.
140-143) and Ramsay and Lisle (2000, pp. 998-999). In this section, a model is developed, which combines the cream-cake model and both Couette and Poiseuille flow.

For Couette flow this simply amounts to considering different boundary conditions (see figure 5):

$$
\begin{aligned}
& u(x, \pm h)= \pm U_{s}, \quad-l \leq x \leq l \\
& v(x, \pm h)=\mp V_{0}, \quad-l \leq x \leq l .
\end{aligned}
$$

By following a similar approach of Jager (1969, pp. 140-143), the velocity field is given by

$$
\begin{gathered}
u(x, y)=\frac{3 V_{0} x\left(h^{2}-y^{2}\right)}{2 h^{3}}+\frac{U_{s}}{h} y \\
v(x, y)=\frac{V_{0} y\left(y^{2}-3 h^{2}\right)}{2 h^{3}} .
\end{gathered}
$$

It is important to remember that $h$ is a function of time $t$ due to the boundary condition that the velocity is $V_{0}$ at $y=h$. Therefore $h(t)=V_{0} t+h_{0}$, where $h_{0}$ is the initial shear zone half-width.
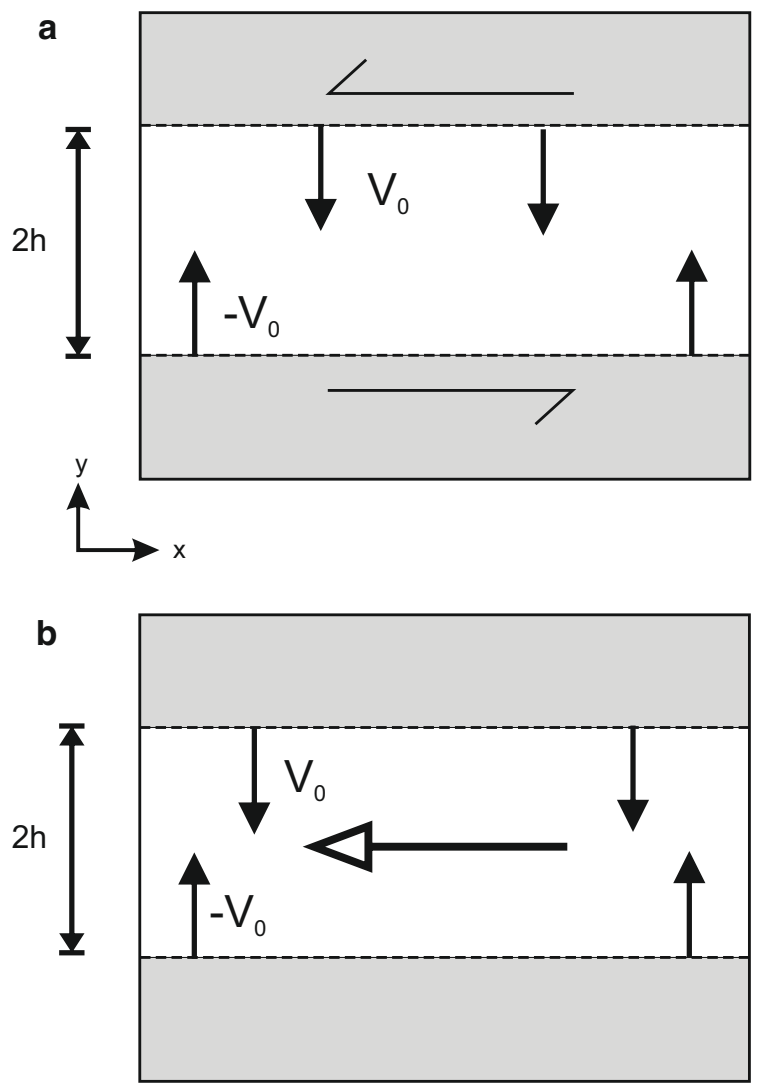

Figure 5. This is a depiction of the cream-cake model combined with (a) Couette flow and (b) Poiseuille flow. The grey regions are rigid and are outside the shear zone region between the dashed line. The rigid walls come together with speed $V_{0}$ at $y=h$ and $-V_{0}$ at $y=-h$. 
In the case of Poiseuille flow there is a pressure $(p)$ gradient along the shear zone (Mulchrone and Mukherjee 2016) given by

$$
\frac{d p}{d x}=-G
$$

Using this condition along with the form of the pressure term used by Jaeger (1969, pp. 140-143), the velocity field is given by

$$
\begin{gathered}
u(x, y)=\left(\frac{G}{2 \mu}+\frac{3 V_{o} x}{2 h^{3}}\right)\left(h^{2}-y^{2}\right) \\
v(x, y)=\frac{V_{0} y\left(y^{2}-3 h^{2}\right)}{2 h^{3}}
\end{gathered}
$$

and note that $h$ is a function of time. For shear zones on much smaller scales, where the Poiseuille flow component does not exist, the pressure gradient component $(G)$ is taken to be zero.

\section{Solutions and implications}

\subsection{Deformable walls}

In the deformable wall model there is a fixed width zone of active shearing within which Couette and/ or Poiseuille flow occurs. At the same time the pure shear is also active across the entire region. Displacement fields for four situations were calculated and are displayed in figures 6 and 7. A general feature of note across all cases is the presence of a smooth, curved transition zone between regions experiencing shear and those regions outside. This is because the pure shear component tends to move material into or out of the zone of active shearing. Curved transition zones are commonly observed in natural examples (see, e.g., figure $2 \mathrm{a}$ and $\mathrm{b}$ ).

Figure 6(a) is the Couette flow with pure shear such that the extension is along the length of the zone of active shearing. This corresponds to a transpressive regime. The maximum extent of the material experiencing the Couette flow is $2 h$ as the kinematics dictates that the material is entering the shear zone and is subjected to a simple shear. On the other hand, in figure 6(b) the extension direction is normal to the direction of the long axis to the zone of active shearing and corresponds to transtension. In this case the zone of sheared material progressively widens the material, which was previously subjected to Couette flow, is moved outside the zone of active shearing due to the pure shear component.

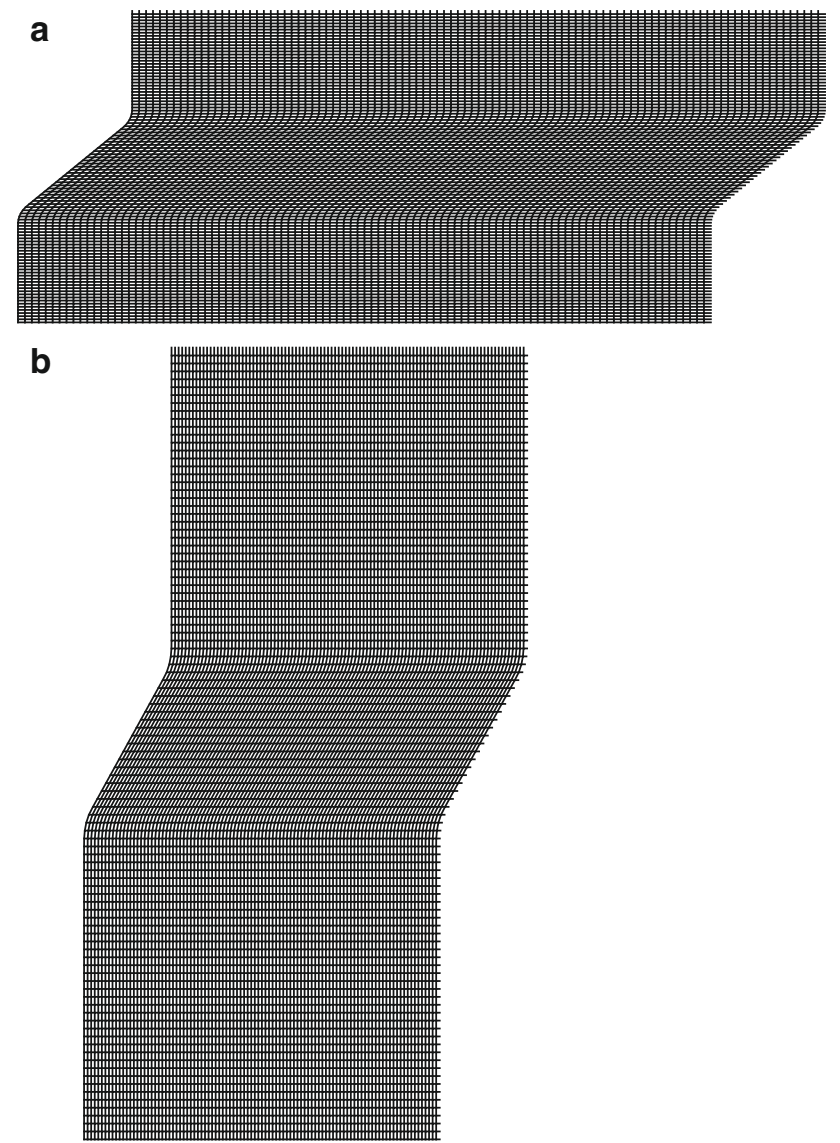

Figure 6. (a) Displacement field for deformable walls with dextral simple shear combined with pure shear with its direction of extension along the length of the shear zone. (b) Displacement field for deformable walls with dextral simple shear combined with pure shear with its extension direction normal to the shear zone length.

In figure $7(\mathrm{a})$ pure shear is directed such that the direction of extension makes an angle of $45^{\circ}$ with the zone of shearing. In this case, the extent of sheared material widens away from the centre of the shear zone. This may correspond to natural examples where shear zones widen as they taper away along their length (see, e.g., Simpson 1983; Ingles 1986). The result of Combined Couette and Poiseuille flow with transpressive pure shear is illustrated in figure $7(\mathrm{~b})$. Here the smooth curving boundaries as well as the extrusive nature of the flow are in evidence. The most intense deformation is present towards the base of the flow.

\subsection{Mobile walls}

In these models the cream-cake model is combined with the Couette and/or Poiseuille flow. In the well-established cream-cake model, it is assumed that the walls are rigid but mobile, and the 


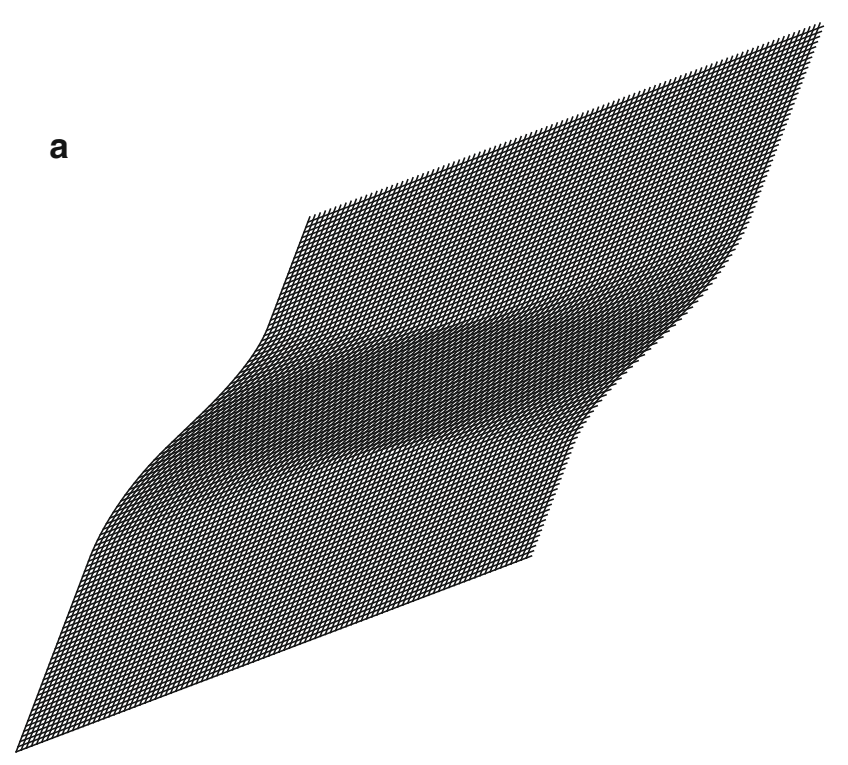

b

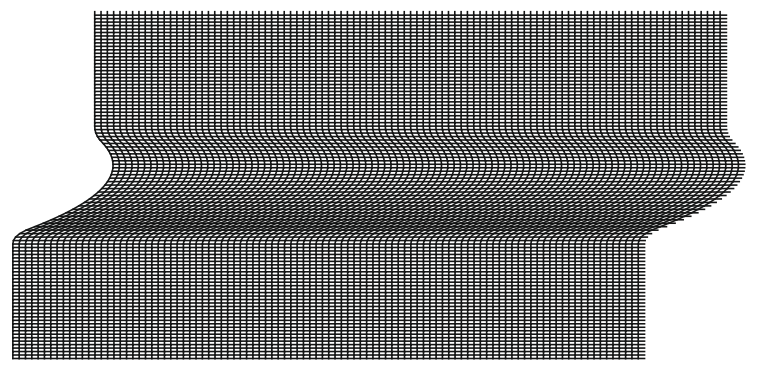

Figure 7. (a) Displacement field for deformable walls with dextral shear and pure shear with extension direction at $45^{\circ}$ to the shear zone. (b) Displacement field for dextral shear combined with Poiseuille flow (positive pressure gradient) and pure shear with extension along the length of the shear zone.

material between them is behaving in a ductile manner. Although the walls may simply move closer to each other by moving perpendicular to the shear zone length, they may also move in mutually opposite directions along the length of the shear zone. Thus, we consider a "cream-cake" model combined with the standard simple shearing. Furthermore, by allowing a pressure gradient along with the length of the shear zone, mobile walls, simple shearing and Poiseuille flow are combined. The velocity patterns are studied here in terms of the kinematic vorticity number (Ghosh 1987). Vorticity patterns are illustrated in figure 8 and blue hues indicate the sinistral shear whereas yellows and reds indicate the dextral shear. When the walls are mobile in the absence of either Couette or Poiseuille flow, then it is the cream-cake model alone (see figure 8a). In this case the vorticity distribution is perfectly symmetrical and consists of alternating quadrants of sinistral and dextral dominated flow. When the dextral simple shear flow is combined with the cream-cake model (figure $8 \mathrm{~b}$ ), then the dextral shear tends to dominate and forms an axisymmetric pattern. The effect of the Poiseuille flow in combination with cream-cake flow (figure 8c) is to displace the vorticity pattern of the cream-cake model alone (compare with figure 8a). In figure 8c the pressure gradient $G$ is positive resulting in extrusion to the right. Finally, when all three are combined (figure 8d) an axisymmetric pattern is displaced (compare with figure 8b).

\section{Model limitations and discussion}

The models presented here are approximate to first order for several reasons. The model of deformable walls (see figure 4) involves a zone of active shearing which maintains a constant width and spatial configuration (i.e., the region between the dashed lines in figure 4) during its lifetime. This type of behaviour may be expected if there was a change in material properties between inside and outside the zone of active shearing, which is not incorporated into the simple model here. On the other hand, the mobile wall model requires a rigid material outside the actively deforming interior, a feature rarely if ever observed in nature. Furthermore, new minerals typically crystallise during shearing (e.g., Price and Cosgrove 1990) and are likely to modify material properties, whereas constant viscosity is assumed here. Additionally, the presence of melt in a shear zone can also imply a switch from Newtonian to non-Newtonian rheology (Mancktelow 2006). Finally, the volume loss during the shear is another natural phenomenon (Ring 1999), which is not considered here.

Many interesting features are present in the models developed. Having a relatively steady zone of active shearing combined with a larger-scale pure shear deformation can result in smooth transition from high to low strain. If the zone of active shearing and the direction of pure shear is oblique, then inentsity of the deformation tends to decease and widen along the length of the shear zone. These features are typical of natural shear zones. More rigorous cross-checking of these features could be done from natural samples based on the rock samples collected from them in order to check the model sensitivity. If an element of the cream-cake or mobile wall model is a significant factor in the history of a shear zone then a key indicator is a 

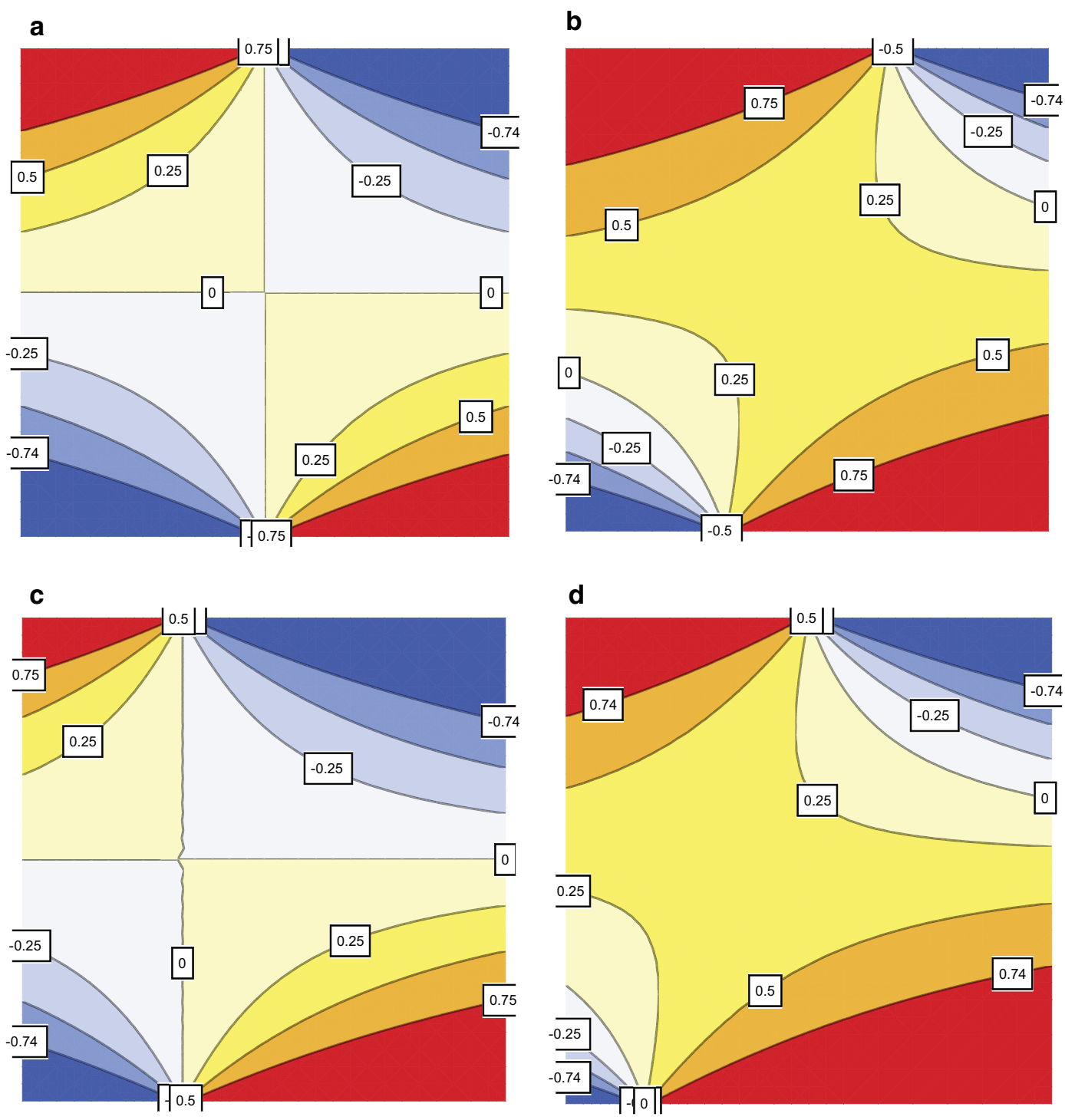

Figure 8. Vorticity field for (a) cream-cake model alone, (b) cream cake plus dextral Couette flow (c) cream-cake plus Poiseuille flow and (d) cream-cake plus Couette and Poiseuille flow.

change of shear sense along the shear zone boundary (e.g., see, figure 8b). If it operates in conjunction with a sinistral (dextral) shear flow, then the shear inside the shear is dominated by sinistral (dextral) shear senses. However, the opposing senses are likely and will be axisymmetrically opposite to each other.

\section{Acknowledgements}

IIT Bombay provided a research sabbatical for the year 2017, and a CPDA grant to SM. PhD student Dripta Dutta (IIT Bombay) partially assisted in arranging a few plates. SM dedicates this work to Prof. Alokesh Chatterjee for teaching him and his batch structural geology with great patience and detail during SM's BSc studies (1996-1999) in the then Presidency College, Kolkata. Saibal Gupta is thanked for handling this paper. Several concerns raised by the two anonymous reviewers greatly clarified the text.

\section{References}

Bailey C M, Francis B E and Fahrney E E 2004 Strain and vorticity analysis of transpressional high-strain zones from the Virginia Piedmont, USA; In: Flow Processes in Faults and Shear Zones (eds) Alsop G I, Holdsworth R E, McCaffey K J W and Hand M, Geol. Soc. Spec. Publ. 224, 249-264.

Bayly M B 1970 Viscosity and anisotropy estimates from measurements of cylindrical folds; Tectonophys. 9 459-474.

Coward M P 1976 Strain within ductile shear zones; Tectonophys. 34 181-197. 
Beaumont C, Jamieson R A, Nguyen M H and Lee B 2001 Himalayan tectonics explained by extrusion of a lowviscosity crustal channel coupled to focused surface denudation; Nature 414 738-742.

Davis G 1983 Shear-zone model for the origin of metamorphic core complexes; Geology 11 342-347.

Fossen H and Cavalcante G C G 2017 Shear zones - A review; Earth-Sci. Rev. 171 434-455.

Gapais D, Bale P, Choukroune P, Cobbold P R, Mahjoub Y and Marquer D 1987 Bulk kinematics from shear zone flattening: Some field examples; J. Struct. Geol. 9 $635-646$

Ghosh S K 1987 Measure of non-coaxiality; J. Struct. Geol. 9 111-113.

Gkains V and Kumar S 2006 Instability of creeping flow past a deformable wall: The role of depth-dependent modulus; Phys. Rev. E 73026307.

Hobbs B E 1972 Deformation of Non-Newtonian Materials in Simple Shear; In: Flow and fracture of rocks (eds) Heard $\mathrm{H}$ C, Borg I, Carter N L, and Raleigh C B, Goephysical Monograph Series, pp. 243-258.

Ingles J 1986 Terminations of ductile shear zones; Tectonophys. 127 87-95.

Jaeger J C 1969 Elasticity, Fracture and Flow with Engineering and Geological Applications. Methuen \& Co Ltd, London.

Lisle R 2014 Strain analysis in dilational shear zones, with examples from Marloes, SW Wales; In: Deformation structures and Processes within the Continental Crust (eds) Llana-Funez S, Marcos A and Bastida F, Geol. Soc. London, Spec. Publ. 394 7-20.

Lister G S and Snoke A W 1984 S-C Mylonites; J. Struct. Geol. 6 617-638.

Lloyd G E 2004 Microstructural evolution in a mylonitic quartz simple shear zone: The significant roles of dauphine twinning and misorientation; In: Flow Processes in Faults and Shear Zones (eds) Alsop G I, Holdsworth R E, McCaffrey K J W and Hand M, Geol. Soc. London, Spec. Publ, 224 39-61.

Lloyd G F, Law R D, Mainprice D and Wheeler J 1992 Microstructural and crystal fabric evolution during shear zone formation; J. Struct. Geol. 14 1079-1100.

Mancktelow N S 2006 How ductile are ductile shear zones? Geology 34 345-348.

Mancktelow N S 2008 Tectonic pressure: Theoretical concepts and modeled examples; Lithos 103 149-177.

Mandal N, Samanta S K and Chakraborty C 2001 Flattening in shear zones under constant volume: A theoretical evaluation; J. Struct. Geol. 22 1771-1780.

Mandal N, Samanta S K and Chakraborty C 2002 Flow and strain patterns at the terminations of tapered shear zones; J. Struct. Geol. 24 297-309.

Marchildon N and Brown M 2003 Spatial distribution of meltbearing structures in anatectic rocks from Southern Brittany, France: implications for melt transfer at grain- to orogen-scale; Tectonophy. 364 215-235.

Mukherjee S 2010 Structures in meso- and micro-scales in the Sutlej section of the higher Himalayan shear zone, Indian Himalaya; e-Terra 7 1-27.

Mukherjee S 2011 Mineral Fish: Their morphological classification, usefulness as shear sense indicators and genesis; Int. J. Earth Sci. 100 1303-1314.
Mukherjee S 2013a Channel flow extrusion model to constrain dynamic viscosity and Prandtl number of the Higher Himalayan Shear Zone; Int. J. Earth Sci. 102 1811-1835.

Mukherjee S 2013b Deformation Microstructures in Rocks; Springer.

Mukherjee S and Biswas R 2014 Kinematics of horizontal simple shear zones of concentric arcs (Taylor Couette flow) with incompressible Newtonian rheology; Int. J. Earth Sci. 103 597-602.

Mukherjee S and Biswas R 2015 Biviscous horizontal simple shear zones of concentric arcs (Taylor Couette flow) with incompressible Newtonian rheology. In: Ductile Shear Zones: From Micro- to Macro-scales (eds) Mukherjee S and Mulchrone KF, Wiley Blackwell, pp. 59-62.

Mukherjee S and Koyi H A 2010 Higher Himalayan Shear Zone, Sutlej section: structural geology and extrusion mechanism by various combinations of simple shear, pure shear and channel flow in shifting modes; Int. J. Earth Sci. 99 1267-1303.

Mukherjee S, Koyi H A and Talbot C J 2012 Implications of channel flow analogue models in extrusion of the Higher Himalayan Shear Zone with special reference to the out-ofsequence thrusting; Int. J. Earth Sci. 101 253-272.

Mukherjee S and Mulchrone K F 2013 Viscous dissipation pattern in incompressible Newtonian simple shear zones: an analytical model; Int. J. Earth Sci. 102 1165-1170.

Mulchrone K F and Mukherjee S 2016 Kinematics and shear heat patterns of ductile simple shear zones with 'slip boundary conditions'; Int. J. Earth Sci. 105 1015-1020.

Passchier C W and Trouw R A J 2005 Microtectonics; 2nd edn, Springer, Berlin.

Pour A B and Hashim M 2016 Geological features mapping using PALSAR-2 data in Kelantan river basin, Peninsular Malaysia. The International Archives of the Photogrammetry, Remote Sensing and Spatial Information Sciences. Vol. XLII-4/W1. pp. 65-70.

Price N J and Cosgrove J W 1990 Analysis of Geological Structures; Cambridge University Press.

Ramsay J G 1980 Shear zone geometry: A review; J. Struct. Geol. 2 83-99.

Ramsay J G and Lisle R J 2000 The Techniques of Modern Structural Geology. Volume 3: Applications of continuum mechanics in structural geology; Academic Press, London.

Regenauer-Lieb K and Yuen D A 2003 Modeling shear zones in geological and planetary sciences: Solid- and fluid-thermal-mechanical approaches; Earth Sci. Rev. 63 295-349.

Ring U 1999 Volume loss, fluid flow, and coaxial versus noncoaxial deformation in retrograde, amphibolite facies shear zones, northern Malawi, east-central Africa; Geol. Soc. Am. Bull. 111 123-142.

Roberts S A and Kumar S 2006 Stability of creeping Couette flow of a power-law fluid past a deformable solid; J. NonNewton Fluid 139 93-102.

Roy Choudhury M, Das S, Chatterjee S M and Sengupta S 2016 Deformation of footwall rock of Phulad Shear Zone, Rajasthan: Evidence of transpressional shear zone. J. Earth Sys. Sci. 125 1033-1040.

Rybacki E, Dimanov A, Huang J, Offerhaus L and Dresen G 2002 High Temperature Deformation-Mechanism Maps for Synthetic Plagioclase Rocks. AGU Fall Meeting Abstract. Schlichting H 1960 Boundary Layer Theory; 4th edn, McGraw-Hill. 
Simpson C 1983 Displacements and strain patterns from naturally occuring shear zone terminations; J. Struct. Geol. 5 497-506.

Turcotte D L and Schubert G 2002 Geodynamics. Cambridge University press, Cambridge, UK

Turcotte D and Schubert G 2014 Geodynamics; Cambridge University Press.

Corresponding editor: SAIBAL Gupta
Vannay J-C and Grasemann B 2001 Himalayan inverted metamorphism and syn-convergence extension as a consequence of a general shear extrusion; Geol. Mag 138 253-276.

Zhang B, Zhu G, Jiang D, Li C and Chen Y 2012 Evolution of the Yiwulushan metamorphic core complex from distributed to localized deformation and its tectonic implications; Tectonics 31 TC4018. 